\title{
Ebaketa-erremintaren tenperaturak neurtzeko tornuko ebaketa eten bidezko fresaketaren simulazioa
}

\author{
(Milling process simulation through interrupted turning \\ process approximation for cutting tools temperatures \\ measuring)
}

Octavio Pereira, Alvaro Martínez, Igor Ansoategui*, Iker Ganzarain, Amaia Calleja

Ingeniaritza Mekanikako Saila. Euskal Herriko Unibertsitatea UPV/EHU

*igor.ansoategui@ehu.eus

DOI: $10.1387 /$ ekaia.16354

Laburpena: Lan honetan zehar fresaketa bidezko simulazioa lantzen da tornuko ebaketa etenaren bitartez. Finkatutako helburu nagusia erremintaren jaulkitze-aurpegian lortuko diren tenperaturak ezagutzea izango da ebaketa prozesuan. Helburu hori lortzeko, torneaketa prozesutik fresaketa prozesura estrapolazio bat egingo da, luzeran artekatutako pieza torneatzen bada posible izango dena, torneaketa fresaketa izango balitz bezala simulatuz, fresaketa ebaketa etena denez. Proba-baldintzetan tenperaturaneurketa horiek gauzatzeko $\mathrm{K}$ motako termoparea erabiliko da, zein jaulkitze aurpegiarekiko 0,5 mm-ko distantziara kokaturik egongo den. Bero-transmisiozko modelo teoriko batean oinarrituz kalkulatuko dugu kontaktuko batez besteko tenperatura. Ebaketa-baldintza ezberdinetarako proba ezberdinak garatu dira eta sakontasunez deskribatuko ditugu. Horretaz gain, ebaketa jarraituan eta etenean lortuko diren tenperatura-diferentziak aztertuko dira, alde batetik, ebaketa-denbora berbera erabiliz eta, bestetik, ebaketa eraginkorraren luzera berbera erabiliz.

Hitz gakoak: Tenperatura-neurketa, torneaketa, fresaketa, mekanizazio-simulazioa.

Abstract: In this work, milling simulation through interrupted turning process approximation is carried out. The main objective is to obtain cutting tool temperatures in the tool rake surface during the cutting process. In order to obtain these values, the milling process is approximated by the turning process. It is possible to assume this simplification when a longitudinally grooved workpiece is turned. This way, turning interrupted processes can be equate to milling processes due to milling interrupted cutting singu- 
Octavio Pereira, Alvaro Martínez, Igor Ansoategui, Iker Ganzarain, Amaia Calleja

larity. The tests measurements were carried out with a K-type thermocouple located at $0,5 \mathrm{~mm}$ from tool insert rake surface. The middle temperature value measured in the contact area will be estimated with a heat conduction theoretical model. Different trails with several cutting conditions are tested. Moreover, temperature difference between continuous and interrupted cutting for the same cutting time and cutting effective length is also studied.

Keywords: Temperature measurement, turning, milling, machining simulation.

\section{HASIERAKO BALDINTZAK}

Aipatutako simulazioan finkatutako helburuak lortzeko proba serie batzuk egin dira, LEALDE TCN 10 ereduko torneaketa-zentroan garatu direnak.

Proba horiek bi material ezberdinekin egin dira. Alde batetik, $35 \mathrm{Hrc}$ ko gogortasuna duen AISI 4340 (F1272, 40NiCrMo7) altzairua dugu; oso gogorra eta mekanizagarritasun zaila duena. Ondorioz, oso interesgarria izango da lortutako tenperaturak aztertzea [1,2]. Bestalde, AW 2030 HB108 aluminioa dugu; aurretik lortutako tenperaturekin konparazioak egiteko hautatu dugu material hau proba hauetan. Ohikoena, aluminioaren kasuan, altzairuarekin lortutako tenperaturak baino baxuagoak lortzea izango da, gogortasun baxuko materiala baita. Erabilitako probetak $60 \mathrm{~mm}$ diametrodun pieza zilindrikoak izan dira, $300 \mathrm{~mm}$-ko luzera eta $240 \mathrm{~mm}$ ko ebaketa erabilgarriko luzera dutenak. Makinaz, erremintaz eta piezez gain, $\mathrm{K}$ motako termopare bat behar izan dugu probetan tenperaturak neurtzeko, taladrina hozgarridun probetarako, datuak eskuratzeko txartel batez hornitutako ordenagailuak, aipatutako ordenagailuan voltetatik graduetara bihurtzeko programa (Labview 6.0) [4] eta seinale-anplifikadorea (0-10 V, 0-1.200 $\left.{ }^{\circ} \mathrm{C}\right)$.

\section{METODOLOGIA}

Artikulu honetan zehar, bi azterketa bereizgarri landuko ditugu, bakoitza dagokien aldagaiekin, baina, beti ere, denak elkarren artean modu zuzenean erlazionatuta.

\subsection{Egonkortasun-tenperaturaren aldaketa $\Theta_{\text {máx }}$ biraketa angeluaren arabera}

Egingo dugun lehenengo ikerketa $\theta_{\text {máx }}$ angeluaren balio ezberdinetarako fresaketa tangentzialaren prozesuan neurtutako tenperaturaren egonkortasuna izango da. Aluminio eta altzairuzko probetarako, egonkortasun- 
tenperaturak grafiko berdinetan islatuko ditugu eta $\theta_{\text {máx }}$ balio bakoitzerako grafiko ezberdina erabiliko dugu. Datuak egokiak badira, altzairuan baino dezente baxuagoa izango den egonkortasun-tenperatura lortu beharko genuke ebaketa etengarrian. Guztira 11 pasada egingo ditugu eta bakoitzean $\theta_{\text {máx }}$-aren balio ezberdina erabiliko dugu. Proba bakoitza lehorrean, MQLarekin [3] [5] [6] eta taladrina bidez errepikatuko dugu.

\subsection{Egonkortasun-tenperaturaren konparaketa jarraituan eta etenean}

Bi aieruzko usteren arabera egingo dugu konparaketa; lehenik, mozketa-denbora berarekin, eta bigarrenik, mozketa eraginkor luzapen berarekin.

Ebaketa-denbora beraz hitz egiten ari garenean, mozten ari garen piezaren luzera bera dela esan nahi dugu, edo, beste modu batean esanda, torneaketa eragiketak irauten duen denbora bera dela. Logikoki, piezaren luzera berbera zilindratzen ari bagara, mozten ari garen material kantitatea askoz ere txikiagoa izango da ebaketa etengabean ebaketa jarraituan baino. Horregatik, lehenengo kasuan lortzen den egonkortasun-tenperatura bigarren kasuan lortzen dena baino baxuagoa izango da.

Ebaketa eraginkor berberaz ari garenean, mozten ari deneko luzeraz ari gara. Beraz, zulatutako piezan, luzera berbereko jarraipeneko piezan mozten ari garen bostena mozten ari gara. Ondorioz, hipotesi hori indarrean jartzeko, totxoaren luzeraren bostena hartuko dugu. Etengabekoaren aurrean, jarraitasuneko egonkortasuna behatuko dugu.

Proba horiek, altzairurako eta aluminiorako egingo ditugu, eta grafiko ezberdinetan azalduko ditugu. Proba horiek lehorrean eta taladrinan errepikatuko ditugu.

\section{BALIOKIDETASUNAK ETA KALKULUAK}

Gauzatu nahi dugun ikerketa, torneaketa etengabearen bidezko fresaketaren simulazioa da, baina ikerketa honek zenbait kalkulu matematiko behar ditu analogia hori bidezkoa izan dadin.

Ondoren, irudi bat ikusiko dugu (1. irudia), non etengabeko torneaketaren bidezko fresaketaren simulazioa laburbiltzen den.

$$
\begin{aligned}
& \mathrm{Bol}_{v 1}=\mathrm{Bol}_{v 2} \\
& f_{z}=f_{t}=l_{c 2} \Rightarrow a_{r}=0,6365 \cdot a_{a} \\
& \alpha_{1}=\alpha_{2} \Leftrightarrow \frac{\theta_{\text {max }}}{\pi \cdot D} \approx \frac{l_{c}}{L} \Leftrightarrow \beta_{1}=\beta_{2}
\end{aligned}
$$


Octavio Pereira, Alvaro Martínez, Igor Ansoategui, Iker Ganzarain, Amaia Calleja
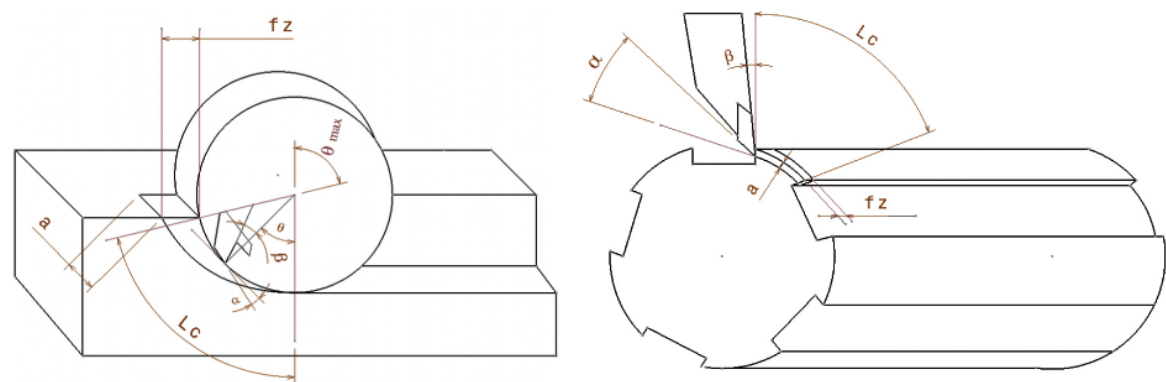

1. irudia. Oinarrizko parametroak fresaketan (1) eta torneaketan (2).

Kalkuluetarako erabiliko dugun fresa bi hortzekoa eta $12 \mathrm{~mm}$-ko diametrokoa izango da. Material bakoitzarentzat tornuan probak egiteko $n_{t}=800$ bira/min-ko bira-abiadura erabiliko dugu eta $f=0,2 \mathrm{~mm} /$ bira-ko aitzinapena.

Aurretik lortutako hasierako datuak kontuan izanda, baliokidetasun parametroak kalkulatuko ditugu.

\subsection{Biraketa-abiadura baliokidea fresaketan}

Alde batetik, abiadura periferikoaren adierazpena dugu:

$$
v_{t}=v_{f} \rightarrow w_{t} \cdot r_{t}=w_{f} \cdot r_{f}
$$

non: $v_{t}=$ abiadura periferikoa torneaketan $(\mathrm{m} / \mathrm{s}), v_{f}=$ abiadura periferikoa fresaketan $(\mathrm{m} / \mathrm{s}), w_{t}=$ errotazio-abiadura torneaketan $(\mathrm{rad} / \mathrm{s}), w_{f}=$ errotazio-abiadura fresaketan $(\mathrm{rad} / \mathrm{s}), r_{t}=$ piezaren erradioa torneaketan $(\mathrm{m}) \mathrm{y}$, $r_{f}=$ fresaren erradioa $(\mathrm{m})$.

Emandako datuak aurreko adierazpenean ordezkatuz, honakoa lortuko dugu:

$$
800 \cdot \frac{2 \cdot \pi}{60} \cdot 0,03=w_{f} \cdot 0,06 \Rightarrow w_{f}=418,879 \cdot \frac{60}{2 \cdot \pi}=4000 \mathrm{bira} / \mathrm{min}
$$

Kontuan hartu behar dugu, materiala jaten dugun heinean, piezaren erradioaren $r_{t}$ balioak behera egingo duela. Ondorioz, eginiko probetan errotazio-abiadura konstante mantentzean, fresaren errotazio-abiadurak behera egingo du eta balioa $3.000 \mathrm{bira} / \mathrm{min}$-ko izatera iritsiko da.

\subsection{Aitzinapen-baliokidetasuna fresaketan}

$0,2 \mathrm{~mm} /$ rev-eko torneaketa-aitzinapena aintzakotzat hartu dugu. Bi kasuetan kontuan hartu behar dugu aitzinapena bera izan behar dela, eta baita 
ere jaten ari gareneko zatia zein den. Piezak 5 arteka eginda dituela jakinik, eta fresaketa-pieza 10 zatitan banatuko dutela (zati bakoitzak duen angelua ezezaguna delarik), honako adierazpena dugu:

$$
f_{\text {zatia }}=f_{z} \quad \frac{0,2 \mathrm{~mm} / \mathrm{bira}}{2 \cdot \pi / \theta}=f_{z}
$$

non: $f_{\text {zatia } \mathrm{t}}=$ tornuaren piezaren aitzinapena zatiko den, $f_{z}=$ aitzinapena hortzeko fresaketan, eta $\theta=$ zati bakoitzaren angelua.

\subsection{Ebaketa Prozesuen Baliokidetasuna}

Bi ebaketa prozesuetan baliokidetasuna lortzeko bi gauza hartu behar ditugu kontuan. Alde batetik, mozketa-luzera, ebaketa-denbora bera izan dadin bi kasuetan analogoa izatea lortu behar duguna. Bestetik, txirbilaren bolumena, bi kasuetan jandako materiala berdina izan dadin analogoa izatea lortu behar duguna.

Ondorioz, aurreko kontsiderazioak kontuan hartuz, $a_{p}$ ebaketaren sakontasuna aldagai bakar bezala utziz, bi ekuazio lortuko ditugu:

$$
l_{c}=\frac{d_{f}}{2} \cdot \theta_{\max } \pm a_{p} \frac{V_{f}}{V} \sqrt{\frac{d_{f}}{a_{p}}-1}
$$

non $f_{z}=$ aitzinapena hortzeko den, $d_{f}=$ fresaren diametroa, $a_{p}=$ ebaketaren sakontasuna, $V_{f}=$ aitzinapen-abiadura, eta $V=$ ebaketa-abiadura.

Fresaketaren geometriaren arabera (2. irudia):

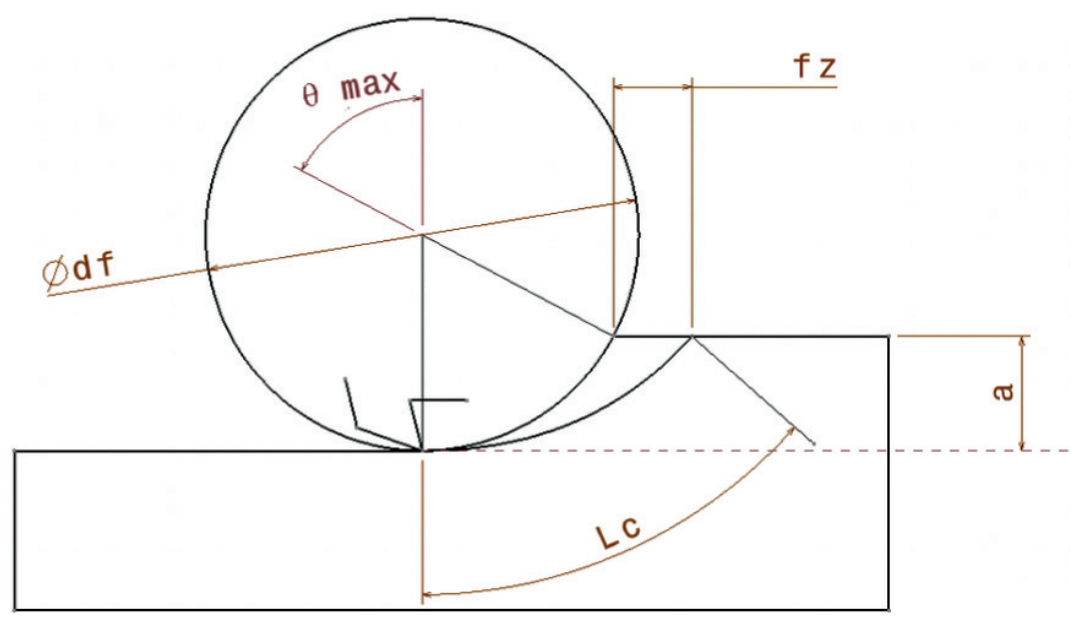

2. irudia. Ebaketa-geometria fresaketan. 
Octavio Pereira, Alvaro Martínez, Igor Ansoategui, Iker Ganzarain, Amaia Calleja

Alde batetik, fresaketan erauzitako bolumena aldi bakoitzean honela sinplifikatuz:

$$
\operatorname{Vol}_{f}=f_{z} \cdot d_{f} \cdot a_{p}
$$

Horretaz gain, torneaketan erauzitako txirbil-bolumena kontuan hartuz:

$$
Q=\frac{1000 \cdot V \cdot a_{p} \cdot f}{60}
$$

Fresaketaren aldi bakoitzean erauzitako bolumena torneaketa zati bakoitzean erauzitako materialarekin berdintzean, honakoa lortuko dugu :

$$
f_{z} \cdot d_{f} \cdot l \cdot\left(\mathrm{mm}^{3}\right)=\frac{\frac{1000 \cdot V \cdot a_{p} \cdot f_{z}}{60} \cdot\left(\frac{\mathrm{mm}^{3}}{\mathrm{seg}}\right) \cdot \frac{1}{n_{t}} \cdot\left(\frac{\mathrm{min}}{\mathrm{rev}}\right) \cdot 60 \cdot\left(\frac{\mathrm{seg}}{\mathrm{min}}\right)}{\frac{2 \cdot \pi}{\theta}}
$$

$1 \mathrm{~mm}$-ko fresaketan pasaldi-sakontasun balio bat hartuko dugu. Aurreko ekuazioa ebazteko abiadura periferikoa behar dugu. Horregatik, lehenik eta behin honakoa kalkulatu beharko dugu:

$$
V=\frac{\pi \cdot d_{t} \cdot n_{t}}{1000}=\frac{\pi \cdot 60 \cdot 800}{1000}=150,796 \frac{\mathrm{m}}{\mathrm{min}}
$$

Ebaketa-abiadura hau totxoaren $60 \mathrm{~mm}$-ko diametro bati egokitzen zaio bakarrik. Ondorioz, diametro ezberdineko pieza batentzat balio ezberdina edukiko du.

Balio hau aurreko ekuazioan ordezkatzen badugu:

$$
\frac{0,2 \cdot \theta}{2 \cdot \pi} \cdot 12 \cdot l \cdot\left(\mathrm{mm}^{3}\right)=\frac{\frac{1000 \cdot 150,796 \cdot a_{p} \cdot \frac{0,2 \cdot \theta}{2 \cdot \pi}}{60} \cdot\left(\frac{\mathrm{mm}^{3}}{\mathrm{seg}}\right) \cdot \frac{1}{800} \cdot\left(\frac{\mathrm{min}}{\mathrm{bira}}\right) \cdot 60 \cdot\left(\frac{\mathrm{seg}}{\mathrm{min}}\right)}{\frac{2 \cdot \pi}{\theta}}
$$

Behatu dezakegun moduan, eragiketak egiteko datu bat gehiago falta zaigu, $\theta$-ren balioa, hain zuzen. Balio hori fresaketan luzerako ebaketaren formulan ordezkatuz lortuko dugu, eta torneaketan izango dugunarekin berdinduz, honako hau izango dugu: 


$$
l_{c}=\frac{d_{f}}{2} \cdot \theta_{\max } \pm a_{p} \frac{V_{f}}{V} \sqrt{\frac{d_{f}}{a_{p}}-1}=r_{t} \cdot \theta
$$

Balioak ordezkatuz honakoa lortuko dugu:

$$
\frac{12}{2} \cdot \pi \pm 0,001 \frac{\frac{\theta}{2 \cdot \pi} \cdot 2 \cdot 4000}{150,796} \cdot \sqrt{\frac{0,012}{0,001}-1}=\frac{60}{2} \cdot \theta \rightarrow \theta=0,628 \mathrm{rad} \approx 36^{\circ}
$$

Espero genuen emaitza da; izan ere, arteka zabalak egiten ari garenez eta luzerako 10 tarte daudenez, tarte bakoitzak $360 / 10=36^{\circ}$ estaliko du. Aurretik aipatu dugun totxo metalikoaren tarteak diametro jakin bateko fresa baten bidez egingo ditugu. Tarte bakoitzaren luzera periferikoa honela kalkulatuko dugu:

$$
l_{\text {tarte }}=r_{1} \cdot \theta=\frac{0,06}{2} \cdot 0,6277=18,831 \mathrm{~mm}
$$

Ondorioz, luzera hori piezaren periferiaren gain neurtuta dagoela kontuan hartuz, balio horren azpitik dabilen diametro zehatz jakin bat duen fresa hautatuko dugu. Kasu honetarako fresen diametro egokienak zein diren aztertzen badugu, ohartuko gara $18 \mathrm{~mm}$-ko diametrodun fresa dela egokiena.

Tarte horiek izango duten itxurarekin eta kontuan hartu behar izango ditugun ezaugarriekin jarraitu baino lehen, falta zaigun datu fundamentala kalkulatu beharko dugu: txirbilaren bolumenaren berdintasunaren ekuazioan ez dugunez beste ezezagunik izango, beharrezkoak diren ordezkapenak egin ahal izango ditugu torneaketan aplikatuko dugun ebaketaren sakonera aurkitu ahal izateko:

$\frac{0,2 \cdot \theta}{2 \cdot \pi} \cdot 12 \cdot l \cdot\left(\mathrm{mm}^{3}\right)=\frac{\frac{1000 \cdot 150,796 \cdot a_{p} \cdot \frac{0,2 \cdot 0,6277}{2 \cdot \pi}}{60} \cdot\left(\frac{\mathrm{mm}^{3}}{\mathrm{seg}}\right) \cdot \frac{1}{800} \cdot\left(\frac{\mathrm{min}}{\mathrm{rev}}\right) \cdot 60 \cdot\left(\frac{\mathrm{seg}}{\mathrm{min}}\right)}{\frac{2 \cdot \pi}{0,6277}}$

Torneaketa diametroetan programatzen dela kontuan hartuz, ebaketasakonera 1,273 mm-koa izango da.

\section{4. $\boldsymbol{\Theta}_{\text {máx }}$ biraketa-angeluari buruzkoak}

Aurretik, zatiak $18 \mathrm{~mm}$-dun fresa baten bidez egingo ditugula aipatu dugu. Ondorioz, fresaren diametroa konstante izatean, piezan sakontzen 
Octavio Pereira, Alvaro Martínez, Igor Ansoategui, Iker Ganzarain, Amaia Calleja

joan ahala, tarte hutsei dagokien 18,831eko magnitudea konstante mantenduko da, nahiz eta material zatiak luzeran txikiagotzen joan. $\theta$ angeluak markatzen duen material zatiak $36^{\circ}$-koa izateari utziko dio, eta balio txikiago batera igaroko da. Angelu-aldaketa horiek fresaketaren $\theta_{\text {máx }}$ angeluan islatuko dira. Modu horretan, materialaren totxo bat bakarrik erabiltzen dugu, $\theta_{\text {máx }}$ balio ezberdinetarako proba ezberdinak egiteko.

1,2745 mm-ko sakontasuna janez, artekak zuen $\theta$ balioa bilatzeko landu genuen prozesuaren alderantzizkoa garatu beharko dugu $\theta_{\text {máx }}$ balioa bilatzeko. Artekaren zabalera finkoa denez, $\theta$ balioan oinarrituz, $\theta_{\text {máx }}$ kalkula dezakegu:

Ondorengo adierazpena betetzen delarik:

$$
L_{c}=\pi \cdot d_{t}
$$

Materialaren artekaren zati bakoitzean luzera honakoa izango da:

$$
l_{\text {arkua }}=\frac{\pi \cdot d_{t}-18,831 \cdot 5}{5}
$$

$l_{\text {arkua }}=\theta \cdot r$ baldin bada:

$$
\theta=\frac{l_{\text {arkиa }}}{r}=\frac{2 \cdot l_{\text {arkиa }}}{d} \quad \theta=\frac{2 \cdot \pi \cdot d_{t}-188,31}{5 \cdot d_{t}}
$$

Honezkero, badugu $\theta$ balioaren eta totxo zilindrokorako diametroaren balioaren arteko erlazioa. Orain erlazio hori erabiltzea besterik ez dugu behar $\theta$ bakoitzari dagokion $\theta_{\text {máx-a }}$ ezagutzeko. Berez, ebaketa-luzerak torneaketan eta fresaketan erlazionatzen zituen formula osoa erabili beharko genukeen arren, gutxi gorabeherako formula erabil dezakegu kalkuluak sinplifikatzeko:

$$
d_{t} \cdot \theta=d_{f} \cdot \theta_{\max } \quad \theta_{\max }=\frac{d_{t} \cdot \theta}{d_{f}} \quad \theta_{\max }=\frac{2 \cdot \pi \cdot d-188,31}{5 \cdot d_{f}}
$$

Kalkulatutako ap-ren balioa kontuan hartuta, diametro balio ezberdinentzat $\theta_{\text {máx }}$ balio ezberdinak kalkulatu ahal izango ditugu, eta ondorioz, modu horretan tenperaturak angeluaren balioarekin nola aldatzen diren aztertu ahal izango dugu.

1. pasaldia $\Rightarrow d=58,7255 \rightarrow \theta_{\text {máx }}=712,53^{\circ}$

2. pasaldia $\Rightarrow d=57,4510 \rightarrow \theta_{\text {máx }}=164,88^{\circ}$

3. pasaldia $\Rightarrow d=56,1765 \rightarrow \theta_{\text {máx }}=157,24^{\circ}$ 

4. pasaldia $\Rightarrow d=54,9020 \rightarrow \theta_{\text {máx }}=149,59^{\circ}$
5. pasaldia $\Rightarrow d=53,6275 \rightarrow \theta_{\text {máx }}=141,94^{\circ}$
6. pasaldia $\Rightarrow d=52,3530 \rightarrow \theta_{\text {máx }}=134,29^{\circ}$
7. pasaldia $\Rightarrow d=51,0785 \rightarrow \theta_{\text {máx }}=126,64^{\circ}$
8. pasaldia $\Rightarrow d=49,8040 \rightarrow \theta_{\text {máx }}=118,99^{\circ}$
9. pasaldia $\Rightarrow d=48,5295 \rightarrow \theta_{\text {máx }}=111,34^{\circ}$
10. pasaldia $\Rightarrow d=47,2550 \rightarrow \theta_{\text {máx }}=103,69^{\circ}$
11. pasaldia $\Rightarrow d=45,9805 \rightarrow \theta_{\text {máx }}=96,037^{\circ}$
12. pasaldia $\Rightarrow d=44,7060 \rightarrow \theta_{\text {máx }}=88,387^{\circ}$

Sortutako artekek sakonera finitua izango dute. 0,75 mm-ko sakonera duten artekak egingo ditugu. Lortu ditugun datuentzat 11. pasaldiraino iritsi beharko gara ebaketa etenean sakonera horretara iristeko.

Dagokion ebaketa-abiadura kalkulatu beharko dugu, biraketa-abiadura konstantea eta ezaguna dela jakinik.

Horretaz gain, tarte bakoitza mekanizatzeko behar den denbora kontuan hartzea beharrezkoa da. Horretarako, erregela sinple bat aplikatzea besterik ez dugu behar lehenengo pasaldian. Biraketa-abiadura 800 bira/minutu-ko dela jakinik, eta tarteak biraketaren 1/10 zatia estaltzen dutela:

$$
t=\frac{60}{800 \cdot 10}=0,0075 \mathrm{seg}
$$

\section{TENPERATURAREN EGONKORTASUNA}

Fenomeno hau behar bezala adierazteko, ebaketa-gunean bero-balantzea egitea beharrezkoa da. Ebaketa prozesuan materialaren zizailadura bidez sortuko den beroa, zati batean eroankortasun bidez transmititzen da piezara, eta beste zati batean konbekzio bidez ingurunera. Horrenbestez, bero-sortzaile modura bi kasu ezberdin edukiko genituzke, bat ebaketa etenean, eta bestea, ebaketa jarraituan. Ebaketa etena egiten ari garen bitartean, beroa denbora tarte batzuetan bakarrik sortzen ari garen bitartean, ebaketa jarraituan sortutako beroa konstantea da eta balio jakin bat du.

Orain, beroaren ebakuazioa nola sortzen den ikusi behar dugu, tenperaturaren egonkortasuna nola gertatzen den azaltzeko. Txirbilarekin joango den beroaz gain, erremintara nahiz piezara eroapen bidez ebakuatuko da beroa.

Tenperaturaren egonkortasunera iristen gareneko egoera suposatzen badugu, prozesuan erabiliko dugun formula honakoa izango da:

$$
Q=\lambda_{1} \cdot A_{1} \cdot\left(\frac{\partial \theta}{\partial x_{1}}\right)+\lambda_{2} \cdot A_{2} \cdot\left(\frac{\partial \theta}{\partial x_{2}}\right)+Q_{v}
$$


Octavio Pereira, Alvaro Martínez, Igor Ansoategui, Iker Ganzarain, Amaia Calleja

non: $Q=$ momentuan sortutako beroa, $\lambda_{1}=$ materialaren eroankortasun koefizientea piezan, $\quad \lambda_{2}=$ materialaren eroankortasun koefizientea piezan, $A_{1}$ = beroaren ebakuazio-gainazala piezan, $A_{2}=$ beroaren ebakuaziogainazala piezan, $\left(\frac{\partial \theta}{\partial x_{1}}\right)=$ tenperatura-gradientea piezan, $\left(\frac{\partial \theta}{\partial x_{2}}\right)=$ piezaren tenperatura-gradientea y, $Q_{v}=$ txirbilak ebakuatutako beroa.

\subsection{Cook-en metodo analitikoa}

Cook jaunak 1973. urtean makinazio prozesuan zehar erreminta-txirbil interfasean gertatuko den tenperaturaren handiagotzea aurreikustea ahalbidetzen zuen formula garatu zuen.

$$
T=0,4 \cdot \frac{U}{\rho \cdot C}\left(\frac{v \cdot t_{0}}{K}\right)^{0,333}
$$

non: $T$ : txirbil-erreminta interfasearen batez besteko tenperatura $\left({ }^{\circ} \mathrm{C}\right)$, $U$ : eragiketaren energia espezifikoa $\left(\mathrm{N} \cdot \mathrm{m} / \mathrm{mm}^{3}\right)$, v: ebaketa-abiadura $(\mathrm{m} / \mathrm{s})$ eta, $t_{0}$ : txirbilaren lodiera ebaketa aurretik $(\mathrm{m}), \rho \cdot C$ : materialaren bero espezifiko bolumetrikoa $\left(\frac{\mathrm{J}}{\mathrm{mm}^{3} \cdot{ }^{\circ} \mathrm{C}}\right)$ eta, $K$ : lan-materialaren difusibitate termikoa $\left(\mathrm{m}^{2} / \mathrm{s}\right)$.

Ekuazio horren bidez lortutako tenperaturaren handiagotzeari erreferentziazko tenperatura gehitu behar diogu, normalean giro-tenperatura izango dena:

$$
T\left(V_{C}\right)=\Delta T\left(V_{C}\right)+T_{\text {Erreferentzia }}
$$

non: $T=$ prozesuaren batez besteko tenperatura eta, $T_{\text {Erreferentzia }}=$ erreferentziazko tenperatura (normalean ingurugirokoa).

Orain egindako probentzat Cook-en adierazpena aplikatzen badugu, ebaketa jarraituaren kasuan lortu beharko genukeen tenperatura zein den jakin genezake.

Al-2030 T4 aluminioaren parametroak honakoak dira:

$U=0,56 \mathrm{Nm} / \mathrm{mm}^{3}, v=2,46 \mathrm{~m} / \mathrm{s}, \rho=2,75 \mathrm{~g} / \mathrm{cm}^{3}, c=0,882 \mathrm{~J} / \mathrm{g} \cdot{ }^{\circ} \mathrm{C}, \mathrm{y} \lambda=159 \mathrm{~W} / \mathrm{mK}$ 
Ondorioz, Cook-en adierazpenaren aurreko balioak ordezkatuz honakoa lortuko dugu:

$$
\Delta T=266^{\circ} \mathrm{C}
$$

Horri erreferentziazko tenperatura gehitzen badiogu:

$$
T\left(V_{C}\right)=\Delta T\left(V_{C}\right)+T_{\text {Erreferentzia }}=266+20=286{ }^{\circ} \mathrm{C}
$$

40NiCrMo7 (AISI 4340, F 1272) altzairuaren balioak honakoak dira:

$U=3,61 \mathrm{Nm} / \mathrm{mm}^{3}, v=2,46 \mathrm{~m} / \mathrm{s}, \rho=9 \mathrm{~g} / \mathrm{cm}^{3}, c=0,507 \mathrm{~J} / \mathrm{g} \cdot{ }^{\circ} \mathrm{C}, \mathrm{y} \lambda=44,5 \mathrm{~W} / \mathrm{mK}$

Ondorioz, aurreko balioak Cook-en adierazpenean ordezkatuz eta erreferentziazko tenperatura gehituz:

$$
T\left(V_{C}\right)=\Delta T\left(V_{C}\right)+T_{\text {Erreferentzia }}=1833+20=1853^{\circ} \mathrm{C}
$$

Beraz, lortutako emaitzak probetan lortu genituen emaitzekin alderatuz, desberdintasuna nabaria da. Jaulkitze-aurpegitik $0,5 \mathrm{~mm}$-ko distantziara ezarri dugun termoparearen efektua oso garrantzitsua izan dela beha dezakegu.

\section{EGINDAKO PROBAK}

Lan honen jarraipenak proba esperimental jakin batzuen ikerketa dakar. Ondorioz, «denbora-tenperatura» grafikoen bidez, probetako emaitzetan oinarritutako datuak aurkeztuko ditugu proba ezberdin bakoitzarentzat.

Gainera, proba bakoitza laginketa-denbora desberdinetan neurtu dugula kontutan izan beharko dugu, baina antzeko probetarako, aldiz, laginketadenbora berbera erabiliko dugu.

75 ms-ko laginketa-denbora proba hauetarako nahiko baxua denez, aukera egokiena denbora horren multiplo bat hautatzea izango da. Adibidez, totxoaren 10 biratik behin jaulkitze-aurpegian izango dugun tenperatura neurtu ahal izango dugu, hau da, 750 ms-ko laginketa-denbora hartuko dugu, denbora egokiagoa delako. Proba hauek totxoaren $240 \mathrm{~mm}$-an zehar egitean, tenperaturen laginketaren denbora totala 90 segundokoa izango dela ondorioztatuko dugu. 
Octavio Pereira, Alvaro Martínez, Igor Ansoategui, Iker Ganzarain, Amaia Calleja

1. taula. Egindako proben laburpena.

\begin{tabular}{rccccc}
\hline & $\begin{array}{c}\mathrm{N} \\
(\mathrm{bira} / \mathrm{min})\end{array}$ & $\begin{array}{c}\mathrm{D} \\
(\mathrm{mm})\end{array}$ & $\begin{array}{c}\mathrm{Vc} \\
(\mathrm{m} / \mathrm{min})\end{array}$ & $\begin{array}{c}\mathrm{Lc} \\
(\mathrm{mm})\end{array}$ & $\begin{array}{c}\theta_{\text {máx }} \text { fresaketa } \\
\left({ }^{\circ}\right)\end{array}$ \\
\hline 1. pasaldia & 800 & 58,727 & 147,597 & 240 & 172,53 \\
2. pasaldia & 800 & 57,450 & 144,398 & 240 & 164,88 \\
3. pasaldia & 800 & 56,180 & 141,199 & 240 & 157,24 \\
4. pasaldia & 800 & 54,910 & 138,006 & 240 & 149,59 \\
5. pasaldia & 800 & 53,640 & 134,800 & 240 & 141,94 \\
6. pasaldia & 800 & 52,360 & 131,602 & 240 & 134,29 \\
7. pasaldia & 800 & 51,090 & 128,402 & 240 & 126,64 \\
8. pasaldia & 800 & 49,820 & 125,203 & 240 & 118,99 \\
9. pasaldia & $800 \mathrm{t}$ & 48,540 & 122,004 & 240 & 111,34 \\
10. pasaldia & 800 & 47,270 & 118,795 & 240 & 103,69
\end{tabular}

Orain gure helburua grafikoak beraien artean konparatzea izango da; ebaketan parte hartzen duten parametro bakoitzaren efektuek eragingo dituzten ondorioetara irits gaitezen.

\subsection{Murgilketa konstantearen bidezko grafiko konparatiboak}

Atal honetan lortutako grafiko konparagarriak (3. irudia eta 4. irudia) ikusiko ditugu, kasu honetan murgilketa konstante mantentzen badugu eta aurretik azaldutako ebaketa-baldintzak aldatuz; hau da, lehorrean, MQL-rekin eta taladrinarekin. 

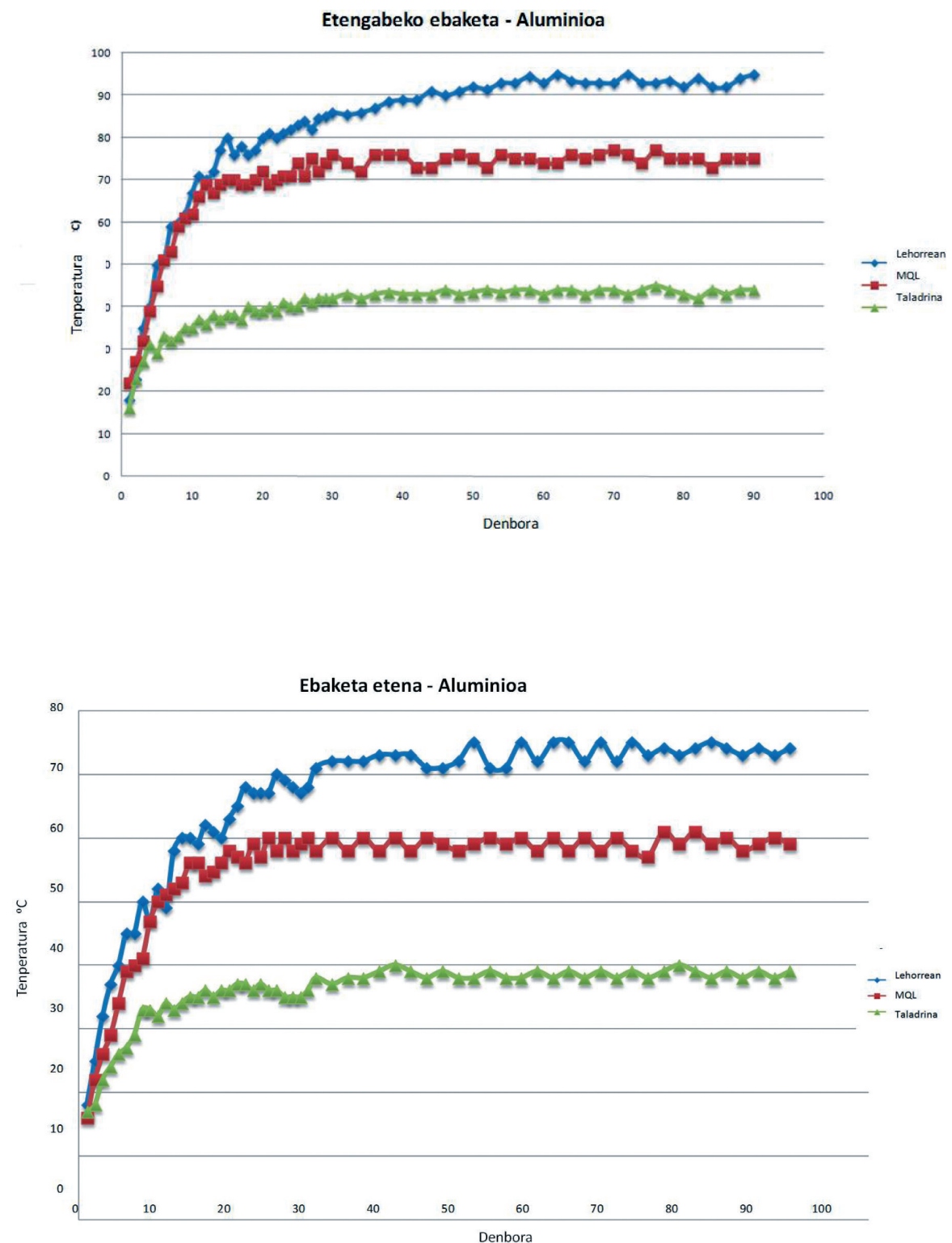

3. eta 4. irudiak. Etengabeko ebaketaren eta ebaketa etenaren bidezko proben grafikoak aluminioarekin. 
Octavio Pereira, Alvaro Martínez, Igor Ansoategui, Iker Ganzarain, Amaia Calleja

5.2. Luzera-Tenperatura proben grafikoak (5. irudia eta 6. irudia)
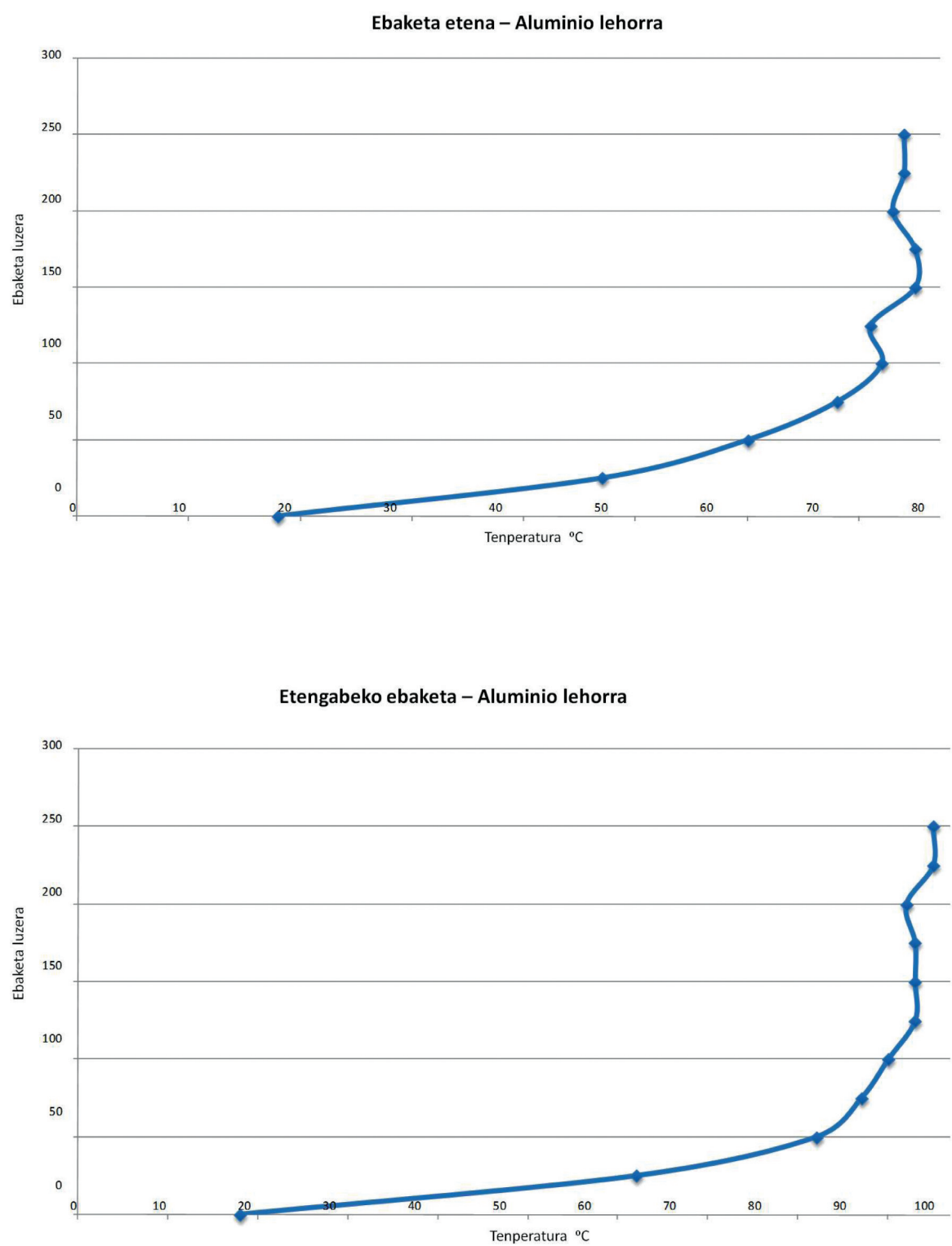

5. eta 6. irudiak. Luzera-Tenperatura proben grafikoak. 


\section{EMAITZEN ANALISIA}

\subsection{Denboraren eta Tenperaturaren azterketa grafikoak}

Aluminiozko murgilketa konstantepeko grafiko konparatiboei dagokienez, taladrina hozgarri era hobeezin modura aurkezten da ebaketa-baldintza jakin hauetarako, MQL metodoaren aurretik, hain zuzen. Taladrinarekin tenperaturaren \% 50eko beherapena gertatuko da, eta MQLaren kasuan $\% 22 \mathrm{koa}$ da.

Bestalde, grafiko konparatiboei behatuz, murgilketa konstantean zehar altzairuan egonkortze-tenperaturak altuagoak dira aluminiozkoetan baino. Izan ere, altzairuak fusio-tenperatura altuagoa du, eta beroarekiko jasangarritasun hobea erakusten du.

Ebaketa etenean zehar, tenperatura altuenak aluminio lehorrarentzat direla ikusiko dugu; hau da, $18-75^{\circ} \mathrm{C}$ inguru, ondoren $16-61{ }^{\circ} \mathrm{C}$ tarteko tenperaturak MQLarentzat eta $17-40{ }^{\circ} \mathrm{C}$ taladrinarentzat. Ondorioz, hozgarri egokiena taladrina izango dela ondoriozta dezakegu.

Bestalde, ebaketa jarraituan zehar, tenperatura altuenak aluminio lehorrarentzat direla behatuko dugu; $18-95{ }^{\circ} \mathrm{C}$ tartean, alegia. Ondoren, 22$76{ }^{\circ} \mathrm{C}$ inguru MQLarentzat eta, azkenik, $16-45{ }^{\circ} \mathrm{C}$ taladrinarentzat. Hemendik, lehen aipatu dugun moduan, taladrina hozgarri egokiena dela ondorioztatzen dugu.

\subsection{Luzera eta Tenperatura azterketa grafikoak}

Lehorreko altzairuaren ebaketa etengabean, tenperaturaren bilakaera handitu egiten da erdigunera iristen den arte, eta $60-70{ }^{\circ} \mathrm{C}$ inguruko balioak lortuko dira. Tenperaturaren egonkortasuna izango dugu, sortuko diren aldaketak mespretxagarriak izango direla-eta.

Bestalde, lehorreko aluminioaren ebaketa jarraituan zehar, piezaren erdiraino tenperaturaren igoera progresiboa jazoko da, $80-100{ }^{\circ} \mathrm{C}$ inguruko balio egonkorrak lortu arte.

Taladrina bidezko mekanizazio etengabean, $100 \mathrm{~mm}$-rainoko luzapena izatera iritsiko gara, eta 35 eta $40{ }^{\circ} \mathrm{C}$ bitarteko tenperatura lortuko dugu. Ondoren, konstante mantenduko da. Aipagarria da, lehorrekoan baino tenperatura baxuagoak ditugula; izan ere, taladrina hozgarri hobea da eta marruskadura proportzio handi batean ekidingo du.

Altzairurako ondorioak berdinak izango dira, ñabardura baten desberdintasunarekin: tenperatura altuagoa izango da altzairuak baino fusio-tenperatura altuagoa duelako. 
Octavio Pereira, Alvaro Martínez, Igor Ansoategui, Iker Ganzarain, Amaia Calleja

\section{ONDORIOAK}

1. Plaketaren jaulkitze-aurpegitik termoparerako $0,5 \mathrm{~mm}$-ko distantzia dela eta, lortutako tenperaturak errealak ez direla frogatzen du Cook-en Legeak. Hala eta guztiz ere, horrek ez ditu aurreko ondorioak baliogabetzen.

2. Murgilketa konstanteko proba konparatiboetan, taladrina hozgarri onena bihurtzen da, MQLaren aurretik.

3. Pasada bakoitzean ebaketa-denborak gora egiten duela behatzen dugu, abiadurak behera egiten duen bitartean. Logikoa den zerbait da; izan ere, ebaketa-denbora kalkulatzeko ebaketa-luzera erabili behar dugu, eta luzera txikiagotzen doa pasaldi bakoitzean. Ebaketa-abiadurarekin gauza bera gertatuko da.

4. Konparaketazko proba etengarri-jarraituetan, tenperaturaren egonkortasun-denbora, mozketa-denboraren baitan dagoela ondoriozta dezakegu, eta ez moztutako materialaren kantitatearen baitan, tenperatura-gradienteen menpean egonik.

5. Gainera, ikus dezakegu materialaren erdia moztean egonkortasuntenperaturaren balioa ez dela bere balioaren erdiraino jaisten; baizik eta, hasierako tenperaturarekiko $1 / 5$. Izan ere, ebaketa etenean mozten dugunean erreminta hozteko aukera dago, eta jarraituan ez, ez baitugu prozesua gelditzen.

\section{BIBLIOGRAFIA}

[1] J. Peláez Vara, El torno. Colección «La Máquina Herramienta» (tomo I), CEDEL, Barcelona (1992).

[2] Shaw M.C., Metal Cutting Principles, Oxford Science Publications, (1989).

[3] Chetan, Behera, B. C., Ghosh, S., and Rao, P. V., 2016, «Wear behavior of PVD TiN coated carbide inserts during machining of Nimonic 90 and Ti6Al4V superalloys under dry and MQL conditions,» Ceram. Int., 42 (13), pp. 14873-14885.

[4] Ponce, P., Ibarra, L., Molina, A., and MacCleery, B., 2012, «Real Time Simulation for DC and AC Motors Based on LabVIEW FPGAs,» IFAC Proc. Vol., 45 (6), pp. 1777-1784.

[5] Sharma, A. K., Tiwari, A. K., and Dixit, A. R., 2016, «Effects of Minimum Quantity Lubrication (MQL) in machining processes using conventional and nanofluid based cutting fluids: A comprehensive review,» J. Clean. Prod., 127, pp. 1-18.

[6] Sharma, A. K., Tiwari, A. K., Singh, R. K., and Dixit, A. R., 2016, «Tribological Investigation of $\mathrm{TiO} 2$ Nanoparticle based Cutting Fluid in Machining under Minimum Quantity Lubrication (MQL),» Mater. Today Proc., 3(6), pp. 2155-2162. 